\title{
In Patients with Obesity, Are Affective Temperaments Associated with Attrition? An Evaluation during and before the SARS-CoV-2 Pandemic
}

\author{
Enrica Marzola ${ }^{1}\left(\mathbb{D}\right.$, Giovanni Abbate-Daga 1,*(D), Elena Scumaci ${ }^{2}$, Valentina Ponzo ${ }^{2}$, Ilaria Goitre ${ }^{2}$, \\ Marianna Pellegrini ${ }^{2}$ (D, Chiara D’Eusebio ${ }^{2}$, Andrea Benso ${ }^{2}$, Sara Belcastro ${ }^{2}$, Franco De Michieli ${ }^{2}$, \\ Chiara Crespi ${ }^{2}$, Fabio Broglio ${ }^{2}$, Ezio Ghigo ${ }^{2}$ and Simona Bo ${ }^{2, * \mathbb{D}}$
}

1 Eating Disorders Center, Department of Neuroscience "Rita Levi Montalcini", "Città della Salute e della Scienza" Hospital of Turin, University of Turin, 10126 Turin, Italy; enrica.marzola@unito.it

2 Diabetes and Metabolic Diseases Unit, Department of Medical Sciences, "Città della Salute e della Scienza" Hospital of Torino, University of Torino, 10126 Torino, Italy; elena.scumaci@ibero.it (E.S.); valentina.ponzo@unito.it (V.P.); ilaria.goitre@libero.it (I.G.); marianna.pellegrini@unito.it (M.P.); chiaradeusi@gmail.com (C.D.); andrea.benso@unito.it (A.B.); sara.belcastro@unito.it (S.B.); franco.demichieli@unito.it (F.D.M.); chiaracrespi@hotmail.it (C.C.); fabio.broglio@unito.it (F.B.); ezio.ghigo@unito.it (E.G.)

* Correspondence: giovanni.abbatedaga@unito.it (G.A.-D.); simona.bo@unito.it (S.B.)

check for updates

Citation: Marzola, E.; Abbate-Daga, G.; Scumaci, E.; Ponzo, V.; Goitre, I.; Pellegrini, M.; D’Eusebio, C.; Benso, A.; Belcastro, S.; De Michieli, F.; et al. In Patients with Obesity, Are Affective Temperaments Associated with Attrition? An Evaluation during and before the SARS-CoV-2

Pandemic. J. Clin. Med. 2022, 11, 862. https://doi.org/10.3390/jcm11030862

Academic Editor: Gianluca Castelnuovo

Received: 14 December 2021

Accepted: 3 February 2022

Published: 7 February 2022

Publisher's Note: MDPI stays neutral with regard to jurisdictional claims in published maps and institutional affiliations.

Copyright: (C) 2022 by the authors. Licensee MDPI, Basel, Switzerland. This article is an open access article distributed under the terms and conditions of the Creative Commons Attribution (CC BY) license (https:// creativecommons.org/licenses/by/ $4.0 /)$.

\begin{abstract}
Timely data on attrition from weight loss programs for patients with obesity during the SARS-CoV-2 pandemic are lacking, so we aimed to contribute to filling this gap in the literature by comparing attrition during or outside of the SARS-CoV-2 pandemic and its possible association with patients' affective temperaments, psychopathology, and clinical variables. Two-hundred and eleven outpatients with obesity were recruited and completed the Temperament Evaluation of Memphis, Pisa, and San Diego Auto-questionnaire, Binge Eating Scale, Beck Depression Inventory, and StateTrait Anxiety Inventory. Those who dropped out during the pandemic period were mostly men, with younger age of weight gain, and with a larger waist circumference than completers. Patients with obesity who dropped out outside of the SARS-CoV-2 pandemic showed marked levels of depression, anxiety, binge eating episodes, and higher affective temperaments (but the hyperthymic one) when compared to their counterparts. The cyclothymic temperament slightly increased attrition (OR $=1.13,95 \%$ CI 1.00-1.27 $p=0.05)$ outside the pandemic, while during the pandemic, male gender $(\mathrm{OR}=3.50,1.04-11.7, p=0.04)$ was associated with attrition. These findings suggested that male patients with obesity are at particular risk of drop-out from weight-loss treatment during the SARS-CoV-2 pandemic; contrariwise, outside the pandemic, affective temperaments could be a useful baseline assessment for defining the attrition risk in these patients.
\end{abstract}

Keywords: attrition; cyclothymic; drop-out; obesity; temperament

\section{Introduction}

The SARS-CoV-2 pandemic has recently proposed a reconceptualization of obesity (and obesity-related metabolic disorders) as a pandemic in the pandemic since it has been authoritatively stated how patients with obesity and metabolic disorders had to face a much hard situation [1] because of a wide array of reasons: First, access to care has been reduced because of the well-known decreased access to primary care providers and the need to reallocate hospital resources [1]. Secondly, obesity is associated with the risk of SARS-CoV2-related death [2] and represents an independent risk for hypoventilation syndromenotwithstanding challenging intubation-in Intensive Care Unit (ICU) patients [3], thus contributing to respiratory failure in patients with acute respiratory distress syndrome [4]. Thirdly, the SARS-CoV-2 outbreak itself entailed a severe mental health burden, mostly in those countries that were strongly hit [5], and this could be of importance in the field 
of obesity, frequently accompanied by sub-threshold affective conditions [6]. Finally, containment measures and fears of infection could have enhanced patients' social isolation, potentially triggering obesity stigma [7].

Treating obesity is challenging, and attrition from weight loss programs is a hallmark of individuals with obesity, being as high as $80 \%$ even before the SARS-CoV-2 outbreak $[8,9]$. Patients who tend to drop out have been commonly described as being younger; reporting other medical comorbidities in addition to obesity; having a high BMI (frequently coupled with failed previous attempts to lose weight); being of low socioeconomic status, job status, or commitment; distance between home and the obesity treatment center; and lack of social support. A wide number of factors has been studied in the field of attrition in obesity, too, such as failure to lose weight, previous attempts at obesity treatment, significative expectation of success, levels of stress, alexithymia, and perceived loneliness, with depression also being associated with attrition for early dropouts [9]. Additionally, body dissatisfaction and the presence of binge eating episodes also represent attritionrelated factors.

In this light, the association between personality traits and attrition from weight loss programs in patients with obesity has been previously studied, although with less consistent results because of the variety of personality assessments performed. Studies adopting a biopsychosocial perspective found low novelty-seeking and high self-directedness as predicting factors for successful short-term weight loss outcomes ( $\leq 6$ months), while low novelty-seeking and high persistence seem to predict better weight loss maintenance, especially after bariatric surgery [10]. On the other hand, the influence between attrition and personality is much more controversial $[10,11]$.

Over the course of the years, other models of personality have been proposed in addition to the well-known biopsychosocial model of personality. In particular, affective temperaments have been proposed as those biological and genetically-based traits of personality that represent our affective basic vulnerability to the environment. The Nineteenth-century psychiatrists Kraepelin and Kretschmer proposed that full-blown affective pathology and premorbid temperaments could shift on a continuum of intensity. Along these lines, Akiskal and collaborators proposed more recently a model by which five temperaments exist: depressive, hyperthymic, cyclothymic, irritable, and anxious. Such an investigation of personality has been increasingly used in psychiatry [12-15], as well as in other fields of medicine [16-18]. Recently, cyclothymic and depressive temperaments have been associated with an increased risk of moderate-to-severe psychological distress following the SARS-CoV-2 outbreak [19]. A previous study reported marked scores on the cyclothymic, irritable, and anxious temperaments in patients with obesity [20]. Additionally, an association between the cyclothymic temperament and the risk of binge eating and a protective effect of hyperthymic temperament on both binge eating and multiple weight cycling have been suggested [16].

Nevertheless, to the best of the authors' knowledge, no studies so far investigated the potential association between affective temperaments of outpatients with obesity in a realworld setting and their risk of attrition by taking into account the limitations imposed by the lockdown due to the SARS-CoV-2 infection. With more detail, we designed this study to (a) investigate if patients with obesity who dropped out during the SARS-CoV-2 pandemic (i.e., seeking treatment from March 2020 until March 2021) differed from those who dropped out outside the pandemic (i.e., seeking treatment before March 2020) with respect to anxiety and depressive symptoms and binge eating episodes; (b) ascertain whether patients' baseline characteristics and affective temperaments could be predictors of attrition from the weight loss program, in or outside the course of the SARS-CoV-2 pandemic.

\section{Materials and Methods}

This was a retrospective study.

All patients who sought treatment at our obesity unit (Endocrinology Division of the "Città della Salute e della Scienza" Hospital of Torino) from January 2018 until December 
2020 were consecutively included. Inclusion criteria were the following: (a) age 18-75 years; (b) BMI $\geq 30 \mathrm{~kg} / \mathrm{m}^{2}$ and $<45 \mathrm{~kg} / \mathrm{m}^{2}$; and (c) being followed-up for at least 4 months at our obesity unit. Exclusion criteria were: (a) secondary causes of obesity; (b) previous bariatric surgery; (c) known psychiatric disorders diagnosed by an M.D. (including known eating disorders); (d) substance abuse within the last 12 months; and (e) pregnancy.

Patients with a psychiatric illness or secondary/more severe obesity were excluded because attrition in these patients could be linked to the underlying disease and/or concomitant therapy or the weight-loss programs may be different, respectively, with the consequent presence of potential confounding factors. Sixteen patients refused to be enrolled or returned incomplete assessments.

All participants gave their informed consent for the collection and analysis of their data.

The study was approved by the local Ethics Committee and was conducted following the principles of the Declaration of Helsinki.

\subsection{The Weight Loss Program}

Patients were offered 6 meetings over 12 months, with further visits eventually planned according to individual needs. During the scheduled visits, patients received both group sessions focusing on nutritional education and improvement of both awareness and selfcontrol, and individual visits by endocrinologists, psychologists, and dieticians. All patients were offered an individually prescribed diet in accordance with the Mediterranean diet composition; an energy restriction could apply on the basis of individual caloric requirements and usual assumptions. Written and verbal recommendations were given to all patients, by focusing on practical lifestyle tips.

During the SARS-CoV-2 pandemic, starting from March 2020, group sessions were abolished, and all visits were carried out on an individual level. In particular, during the period of strict lockdown (i.e., during March, April, October, and November 2020), most visits were carried out remotely, through telemedicine.

The weight loss target was individualized and discussed with the patient. Generally, a $10 \%$ weight loss at 6 months was proposed. However, more or less stringent goals were suggested based on individual needs. All patients were followed for at least 1 year, even if they had achieved their weight loss goal before the end of the program.

\subsection{Assessments}

Our weight loss program has been previously described [9,16]. Weight and height were measured with the participants wearing light clothes and no shoes, respectively, by a mechanical column scale (SECA model 711, Seca GmbH \& Co, Hamburg, Germany) and a Stadiometer (SECA 220 measuring rod, Seca GmbH \& Co, Hamburg, Germany). Waist and neck circumferences were assessed by a plastic tape meter at the umbilicus level or under the cricoid cartilage, respectively.

All patients completed the following questionnaires:

- Temperament Evaluation of Memphis, Pisa, and San Diego Auto-questionnaire, Italian version (TEMPS-A [21]): It is a self-report instrument of 110 (109 for males) items assessing the following affective temperaments: hyperthymic, depressed, irritable, cyclothymic, and anxious;

- $\quad$ Binge Eating Scale, Italian version (BES [22]): A binge eating disorder was considered unlikely with scores of $0-16$, possible with scores of 17-27, and likely with scores $>27$;

- $\quad$ Beck Depression Inventory (BDI [23]): It is a questionnaire aimed at investigating depressive symptoms: Scores from 0 to 4 indicate minimal depressive symptoms, scores of 5-7 indicate mild depression, scores of 8-15 indicate moderate depression, and scores of 16-39 indicate severe depression;

- $\quad$ State-Trait Anxiety Inventory (STAI [24]) for both trait (stable) and state (current) anxiety. The anxiety scores range from 20 to 80 , with higher values corresponding to higher anxiety. 
The above psychometric questionnaires were checked and assessed by a trained psychologist.

\subsection{Definitions}

Patients who did not attend a scheduled appointment and declared they no longer want to participate in the program were considered to be dropouts [9]. In the present study, all the enrolled patients (from January 2018 until December 2020) were divided according to the period of attrition. The SARS-CoV-2 pandemic period started in Italy in March 2020. The dropouts of our obesity unit starting from March 2020 until March 2021 were considered as attritions during the pandemic period (SARS-CoV-2-drop group); the dropouts before March 2020 were considered as attritions outside the pandemic period (non-SARS-CoV-2-drop group).

Weight cycling was defined as intentional weight loss of $\geq 3 \mathrm{~kg}$ followed by involuntary weight regain of $\geq 3 \mathrm{~kg}$ in line with the literature [25,26]; patients experiencing $\geq 2$ cycles were considered as multiple weight cyclers [26].

\subsection{Statistical Analyses}

Kolmogorov-Smirnov test was used to assess the distribution of the variables; the t-Student's and chi-square tests, when appropriate, were used to evaluate between-group differences. Because the distributions of the BDI and the TEMPS-A scores were skewed, the Mann-Whitney test was employed to evaluate the between-group differences. A multiple logistic regression model was used to evaluate the associations between the risk of attrition, either overall or by the period of attendance to the obesity unit, and variables that resulted significantly different between groups (Statistica 10.0, StatSoft GmbH, Tulsa, Ok, USA).

\section{Results}

\subsection{Sociodemographic and Clinical Characteristics of the Sample}

We analyzed 211 patients who met the inclusion criteria. Most were women and reported adverse events during their lifetime (e.g., bereavement, abortion, divorce, abandonment, job loss) (Table 1). More than $40 \%$ of the cohort was living alone, not working/retired, and reported multiple weight cycling. A high prevalence of episodes of binge eating was detected, even if the presence of a full-blown psychiatric disorder represented an exclusion criterion for this study.

\subsection{Characteristics of Patients Who Dropped Out during and outside the Pandemic Period}

Around $40 \%$ of participants received or should have received a visit to our obesity unit during the pandemic period (from March 2020 to March 2021). The characteristics of the patients visited during or outside the pandemic period are described in Supplementary Table S1. The former showed increased mental well-being, lower adverse events, and a higher degree of weight cycling (Supplementary Materials, Table S1).

The characteristics of patients who dropped out during and outside the pandemic period are described in Table 2. Overall, 45\% percent of our patients dropped out: $39.3 \%$ during the pandemic period and $49.2 \%$ outside the pandemic period. 
Table 1. Characteristics of the whole cohort and by the risk of attrition.

\begin{tabular}{|c|c|c|c|c|}
\hline & \multicolumn{4}{|c|}{$\begin{array}{l}\text { Total Sample of People with Obesity } \\
\qquad n=211\end{array}$} \\
\hline & \multirow{2}{*}{$\begin{array}{c}\text { All } \\
n=211\end{array}$} & \multicolumn{2}{|c|}{ Attrition } & \multirow[t]{2}{*}{$p$} \\
\hline & & $\begin{array}{c}\text { Yes } \\
n=95\end{array}$ & $\begin{array}{c}\text { No } \\
n=116\end{array}$ & \\
\hline \multicolumn{5}{|l|}{ Clinical variables } \\
\hline Age (years) & $46.7 \pm 15.3$ & $44.5 \pm 15.4$ & $48.6 \pm 15.1$ & 0.06 \\
\hline Males (\%) & 21.8 & 24.2 & 19.8 & 0.44 \\
\hline Residing in a rural area (\%) & 17.5 & 21.1 & 14.7 & 0.22 \\
\hline Active smoker $(\%)$ & 16.6 & 17.9 & 15.5 & 0.64 \\
\hline Living alone (\%) & 47.4 & 47.4 & 47.4 & 0.99 \\
\hline Not working/retired (\%) & 43.6 & 42.1 & 44.8 & 0.69 \\
\hline Secondary schools/graduation (\%) & 66.8 & 64.2 & 69.0 & 0.47 \\
\hline Adverse life events (\%) & 71.1 & 67.4 & 74.1 & 0.28 \\
\hline Multiple weight cycling (\%) & 49.3 & 50.5 & 48.3 & 0.74 \\
\hline Visits during the pandemic & 42.2 & 36.8 & 46.6 & 0.16 \\
\hline Age of weight gain (years) & $26.6 \pm 13.9$ & $24.6 \pm 13.6$ & $28.2 \pm 13.9$ & 0.06 \\
\hline Weight $(\mathrm{kg})$ & $98.8 \pm 16.0$ & $98.3 \pm 16.5$ & $99.2 \pm 15.6$ & 0.70 \\
\hline Height (cm) & $163.8 \pm 8.0$ & $164.3 \pm 8.1$ & $163.4 \pm 7.9$ & 0.45 \\
\hline $\operatorname{BMI}\left(\mathrm{kg} / \mathrm{m}^{2}\right)$ & $36.8 \pm 4.8$ & $36.4 \pm 5.1$ & $37.1 \pm 4.5$ & 0.33 \\
\hline Waist circumference $(\mathrm{cm})$ & $114.6 \pm 12.0$ & $115.1 \pm 11.7$ & $114.1 \pm 12.4$ & 0.54 \\
\hline Neck circumference (cm) & $38.0 \pm 4.1$ & $37.9 \pm 4.2$ & $38.1 \pm 4.0$ & 0.67 \\
\hline \multicolumn{5}{|l|}{ Psychological questionnaires } \\
\hline BDI & $9.4 \pm 6.0$ & $10.2 \pm 6.2$ & $8.8 \pm 5.9$ & $0.11 *$ \\
\hline STAI-state & $46.9 \pm 11.9$ & $46.5 \pm 11.8$ & $47.2 \pm 11.9$ & 0.67 \\
\hline STAI-trait & $48.6 \pm 11.0$ & $49.2 \pm 10.6$ & $48.1 \pm 11.4$ & 0.48 \\
\hline BES & $33.1 \pm 10.4$ & $35.3 \pm 10.3$ & $31.4 \pm 10.1$ & 0.006 \\
\hline \multicolumn{5}{|l|}{ TEMPS-A scores } \\
\hline Depressive & $10.7 \pm 3.6$ & $11.1 \pm 3.7$ & $10.4 \pm 3.6$ & $0.15 *$ \\
\hline Cyclothymic & $8.1 \pm 4.6$ & $9.4 \pm 4.3$ & $7.0 \pm 4.6$ & $<0.001$ * \\
\hline Hyperthymic & $9.1 \pm 4.6$ & $8.9 \pm 4.4$ & $9.3 \pm 4.9$ & 0.58 * \\
\hline Irritable & $5.8 \pm 4.2$ & $6.4 \pm 4.3$ & $5.3 \pm 4.0$ & 0.044 * \\
\hline Anxious & $11.4 \pm 5.6$ & $11.8 \pm 5.4$ & $11.1 \pm 5.8$ & $0.38 *$ \\
\hline
\end{tabular}

* Mann-Whitney U-test; Legend: BDI: Beck Depression Inventory; STAI: State-Trait Anxiety Inventory; BES: Binge eating scale; TEMPS-A: Temperament Evaluation of Memphis, Pisa, Paris, and San Diego Auto-questionnaire.

Those who dropped out during the pandemic period were more frequently males, had a larger waist, and lower age of first weight gain than those who did not drop out. Moreover, no differences in the psychological assessments emerged between those who dropped out during the pandemic and their counterparts (Table 2).

Outside the SARS-CoV-2 pandemic, patients who abandoned the course of treatment did not differ from those who did not dropout with respect to clinical variables; in contrast, those who dropped out outside the SARS-CoV-2 pandemic showed poorer scores on the psychological assessments than completers, reporting more depressive symptoms, traitanxiety, and episodes of binge-eating, as well as higher scores on depressive, cyclothymic, irritable, and anxious affective temperaments (Table 2).

\subsection{Predictors of Attrition}

As shown in Table 3, concerning the predictors for the overall risk for attrition, in a multiple logistic regression analysis, only the TEMPS-A cyclothymic score was significantly associated with overall attrition (Table 3). During the pandemic period, male gender remained associated with the risk of attrition (Table 3). Outside the pandemic period, cyclothymic temperament showed a trend towards significance as a predictor of attrition (Table 3). 
Table 2. Attrition by the period of attendance to the obesity unit.

\begin{tabular}{|c|c|c|c|c|c|c|}
\hline & \multicolumn{3}{|c|}{ Attrition during the Pandemic Period } & \multicolumn{3}{|c|}{ Attrition outside the Pandemic Period } \\
\hline & $\begin{array}{c}\text { Yes } \\
n=35\end{array}$ & $\begin{array}{c}\text { No Attrition } \\
n=54\end{array}$ & $p$ & $\begin{array}{c}\text { Yes } \\
n=60\end{array}$ & $\begin{array}{c}\text { No Attrition } \\
n=62\end{array}$ & $p$ \\
\hline \multicolumn{7}{|l|}{ Clinical variables } \\
\hline Age (years) & $45.9 \pm 14.1$ & $49.6 \pm 16.2$ & 0.27 & $43.7 \pm 16.1$ & $47.6 \pm 14.1$ & 0.16 \\
\hline Males (\%) & 34.3 & 11.1 & 0.008 & 18.3 & 27.4 & 0.23 \\
\hline Residing in a rural area $(\%)$ & 20.0 & 16.7 & 0.69 & 21.7 & 12.9 & 0.20 \\
\hline Active smoker (\%) & 14.3 & 20.4 & 0.47 & 20.0 & 11.3 & 0.18 \\
\hline Living alone $(\%)$ & 37.1 & 51.9 & 0.17 & 53.3 & 43.6 & 0.28 \\
\hline Not working/retired (\%) & 40.0 & 50.0 & 0.36 & 43.3 & 40.3 & 0.74 \\
\hline $\begin{array}{c}\text { Secondary schools/graduation } \\
(\%)\end{array}$ & 65.7 & 74.1 & 0.40 & 63.3 & 64.5 & 0.89 \\
\hline Adverse life events (\%) & 51.4 & 70.4 & 0.07 & 76.7 & 77.4 & 0.92 \\
\hline Multiple weight cycling (\%) & 51.4 & 63.0 & 0.28 & 50.0 & 35.5 & 0.11 \\
\hline Age of weight gain (years) & $23.4 \pm 11.3$ & $29.2 \pm 14.4$ & 0.047 & $25.2 \pm 14.8$ & $27.3 \pm 13.5$ & 0.41 \\
\hline Weight $(\mathrm{kg})$ & $98.8 \pm 15.2$ & $96.7 \pm 13.4$ & 0.49 & $98.1 \pm 17.4$ & $101.4 \pm 17.1$ & 0.29 \\
\hline Height $(\mathrm{cm})$ & $164.8 \pm 8.2$ & $162.8 \pm 7.5$ & 0.26 & $164.0 \pm 8.1$ & $163.9 \pm 8.3$ & 0.99 \\
\hline $\mathrm{BMI}\left(\mathrm{kg} / \mathrm{m}^{2}\right)$ & $36.4 \pm 5.0$ & $36.4 \pm 4.4$ & 0.96 & $36.4 \pm 5.3$ & $37.6 \pm 4.6$ & 0.19 \\
\hline Waist circumference (cm) & $117.2 \pm 12.5$ & $111.9 \pm 11.1$ & 0.038 & $113.9 \pm 11.1$ & $116.1 \pm 13.2$ & 0.34 \\
\hline Neck circumference $(\mathrm{cm})$ & $38.1 \pm 4.2$ & $37.1 \pm 3.8$ & 0.26 & $37.8 \pm 4.2$ & $39.1 \pm 4.0$ & 0.09 \\
\hline \multicolumn{7}{|l|}{ Psychological questionnaires } \\
\hline BDI & $6.7 \pm 5.7$ & $8.6 \pm 6.0$ & 0.07 & $12.2 \pm 5.6$ & $9.1 \pm 5.8$ & 0.002 \\
\hline STAI-state & $42.6 \pm 10.9$ & $46.7 \pm 11.9$ & 0.11 & $48.8 \pm 11.8$ & $47.6 \pm 12.1$ & 0.59 \\
\hline STAI- trait & $43.6 \pm 8.9$ & $47.9 \pm 10.9$ & 0.06 & $52.4 \pm 10.2$ & $48.2 \pm 11.8$ & 0.040 \\
\hline BES & $32.2 \pm 10.7$ & $31.2 \pm 9.9$ & 0.64 & $37.1 \pm 9.7$ & $31.5 \pm 10.3$ & 0.003 \\
\hline \multicolumn{7}{|l|}{ TEMPS-A } \\
\hline Depressive & $9.6 \pm 3.4$ & $10.5 \pm 3.7$ & $0.18 *$ & $12.1 \pm 3.6$ & $10.4 \pm 3.4$ & $0.009 *$ \\
\hline Cyclothymic & $8.3 \pm 3.9$ & $7.0 \pm 5.0$ & $0.13 *$ & $10.0 \pm 4.5$ & $6.9 \pm 4.2$ & $<0.001 *$ \\
\hline Hyperthymic & $10.3 \pm 4.8$ & $9.4 \pm 5.0$ & $0.42 *$ & $8.2 \pm 3.9$ & $9.3 \pm 4.8$ & $0.52 *$ \\
\hline Irritable & $5.1 \pm 4.8$ & $5.1 \pm 4.1$ & 0.85 * & $7.2 \pm 3.9$ & $5.4 \pm 3.9$ & 0.008 * \\
\hline Anxious & $9.5 \pm 4.7$ & $11.8 \pm 6.2$ & 0.07 * & $13.2 \pm 5.4$ & $10.6 \pm 5.5$ & $0.009 *$ \\
\hline
\end{tabular}

* Mann-Whitney U-test; Legend: BDI: Beck Depression Inventory; STAI: State-Trait Anxiety Inventory; BES: Binge eating scale; TEMPS-A: Temperament Evaluation of Memphis, Pisa, Paris, and San Diego Auto-questionnaire.

Table 3. Variables associated with the risk of attrition by the period of attendance to the obesity unit in a multiple logistic regression analysis.

\begin{tabular}{|c|c|c|c|}
\hline & \multicolumn{3}{|c|}{ Overall Risk of Attrition } \\
\hline & OR; $95 \%$ CI & Beta & $p$ \\
\hline BES & $1.02 ; 0.99-1.05$ & 0.022 & 0.16 \\
\hline TEMPS-A Cyclothymic & $1.12 ; 1.03-1.22$ & 0.117 & 0.006 \\
\hline \multirow[t]{3}{*}{ TEMPS-A Irritable } & $0.97 ; 0.89-1.06$ & -0.028 & 0.53 \\
\hline & \multicolumn{3}{|c|}{ Risk of attrition during the pandemic period } \\
\hline & OR; 95 CI & Beta & $p$ \\
\hline Males (\%) & $3.50 ; 1.04-11.7$ & 1.252 & 0.040 \\
\hline Age of weight gain (years) & $0.96 ; 0.93-1.01$ & -0.036 & 0.06 \\
\hline \multirow[t]{3}{*}{ Waist circumference $(\mathrm{cm})$} & $1.02 ; 0.98-1.07$ & 0.023 & 0.28 \\
\hline & \multicolumn{3}{|c|}{ Risk of attrition outside the pandemic period } \\
\hline & OR; 95 CI & Beta & $p$ \\
\hline BDI & $1.05 ; 0.94-1.17$ & 0.042 & 0.37 \\
\hline STAI-state & $0.97 ; 0.91-1.02$ & -0.029 & 0.23 \\
\hline BES & $1.03 ; 0.98-1.08$ & 0.023 & 0.17 \\
\hline TEMPS-A Depressive & $1.01 ; 0.87-1.18$ & 0.012 & 0.87 \\
\hline TEMPS-A Cyclothymic & $1.13 ; 1.00-1.27$ & 0.122 & 0.05 \\
\hline TEMPS-A Irritable & $1.01 ; 0.89-1.15$ & 0.011 & 0.83 \\
\hline TEMPS-A Anxious & $1.03 ; 0.93-1.13$ & 0.024 & 0.62 \\
\hline
\end{tabular}

Legend: BDI: Beck Depression Inventory; STAI: State-Trait Anxiety Inventory; BES: Binge eating scale; TEMPS-A: Temperament Evaluation of Memphis, Pisa, Paris, and San Diego Auto-questionnaire. 
By comparing the two groups of patients who dropped out, scores for anxiety, depression, the corresponding TEMPS-A aspects, and binge eating were higher among those who dropped out outside the pandemic period (Supplementary Materials, Table S2).

\section{Discussion}

There is no doubt that the SARS-CoV-2 outbreak placed a heavy burden on individuals with obesity, and current data on attrition from weight loss programs during the SARSCoV-2 pandemic are greatly lacking. Several main findings emerged from our study: First, individuals with obesity who dropped out during the pandemic period were more frequently men, with younger age of weight gain, and with a larger waist circumference than those who did not abandon treatments. Subjects who sought treatment during the pandemic reported fewer psychiatric symptoms than patients who sought treatment before the pandemic: Psychic factors probably influenced the choice and the possibility of access to treatment, too. Individuals with obesity who dropped out outside the SARS-CoV-2 pandemic period showed marked levels of depression, anxiety, binge eating episodes, and poorer scores on all the affective temperaments (but the hyperthymic one) when compared to their counterparts. Finally, the cyclothymic temperament significantly predicted attrition from the weight loss program, but when focusing on the pandemic period, only the male gender resulted to be a predictor of attrition.

The paucity of the data currently available makes it difficult to compare these findings to other studies. In line with previous studies on attrition in obesity [9], overall, the individuals who dropped out were more frequently males, showed a younger age of weight gain, and a larger waist circumference than completers. Interestingly, notwithstanding the SARS-CoV-2 outbreak, a substantial proportion of the patients was motivated enough to seek treatments with positive compliance during such a critical time.

No psychological differences emerged when comparing completers and non-completers during the pandemic, raising the question of whether the SARS-CoV-2 pandemic itself generated bias in the pool of individuals seeking treatment. This could suggest that the subjects with more mental problems had some difficulties in undertaking a treatment program during the pandemic. Indeed, the SARS-CoV-2 pandemic had notoriously accentuated stress, anxiety, and depression in the general population [27], particularly in subjects with previous psychiatric symptomatology [28]. The comparison between patients visited during and outside the pandemic period (Supplementary Table S1) confirmed that depression and anxiety may have impacted the search for treatment during the pandemic in subjects with more psychiatric symptomatology. In Italy, the overall affected cases reached $4,808,047$ individuals and 132,391 people overall deceased (Ministry of Health update 8 November 2021 [29]); moreover, data reported by the Superior institute of health (update 5 October 2021) on 7910 deaths showed that obesity was present in $11 \%$ of cases [30]. Therefore, those who were motivated enough to seek help during such a critical period could be particularly motivated and "healthy" from a mental health perspective, not being representative of the general population. To the best of the authors' knowledge, no data are currently available on attrition from weight loss programs during the SARS-CoV-2 pandemic, so future lines of research are warranted on these matters. It is noteworthy that male sex has been consistently described as a factor predicting progression to severe SARSCoV-2 [31], so it could be surmised that male patients during the SARS-CoV-2 outbreak could have been more afraid to become infected, potentially interrupting treatments. Along these lines, it should be borne in mind that our treatment center is located in a hospital facility, thus potentially amplifying patients' fears of the risk of contagion.

Relatedly, male gender was also the only predictor of attrition when focusing on the SARS-CoV-2 pandemic period. Our findings are consistent with earlier research reporting male gender as predicting attrition [32]; however, earlier literature associated males with a poor educational level, in turn, a proxy for patients' socioeconomic status. Our data do not support any sociodemographic difference between completers and non-completers, so this 
finding needs further investigation. Again, as aforementioned, the male-related increased risk for SARS-CoV-2 infection [31] may have played a role in this regard.

In contrast, when taking into account people who dropped out outside the SARS-CoV2 pandemic, no differences in baseline-either sociodemographic or clinical-variables emerged. However, those who dropped out reported significantly more compromised psychological profiles, with respect to anxiety and depressive symptoms, as well as binge eating episodes. In addition, all affective temperaments but the hyperthymic one were more markedly expressed. In this regard, our data are in line with earlier research reporting patients who drop out as more depressed, anxious, and prone to binge eating $[9,16]$ than completers. Still, Amann and collaborators [20] also reported similar findings, with individuals with obesity reporting higher scores on all affective temperaments but the hyperthymic one when compared to healthy controls.

Concerning predictors of attrition outside the SARS-CoV-2 pandemic, it is noteworthy that the cyclothymic temperament resulted overall in being associated to a greater risk of drop out. This is of clinical interest since patients with obesity have been proposed to have a variety of subthreshold affective conditions [6], potentially making them more inclined to poor medication adherence [18]. It should also be borne in mind that the cyclothymic temperament could have a role in entailing sensation seeking and self-stimulating behaviors, thus contributing to poor patient compliance. In fact, mood instability could entail compliance instability. In fact, subjects with cyclothymic temperament are impulsive and might use food to control mood instability. Overall, the cyclothymic temperament is thought to underpin the relationship between obesity and mood disorders [6], so although our sample excluded patients with a full-blown psychiatric diagnosis, it cannot rule out that the cyclothymic temperament could have a role in making patients more prone to be less perseverant in pursuing their goals. Finally, it is crucial for clinicians to know that patients with cyclothymic temperament can develop subthreshold or full-phase bipolar disorders and use of antidepressants (such as fluoxetine) may be at risk of triggering a full-blown bipolar form in these patients [33].

In spite of several strengths, including the timely assessment of SARS-CoV-2-related clinical implications for obesity, the comprehensive assessment of multiple variables for all patients, and the "real world" setting, this study suffers from limitations, such as the small sample size deriving from a single-center, thus potentially jeopardizing the generalizability of our results. Furthermore, during the pandemic period, the approach to the patient changed, and during the strict lockdown, visits were carried out remotely, through telemedicine. This might have affected the results of the study. However, there is evidence that visits by telemedicine are as effective as in-person visits, and telemedicine is now considered a safe alternative that can successfully help patients with obesity in weight loss [34-36]. Lastly, the high scores of the Binge Eating Scale questionnaire we found in our patients suggest that some subjects could have minimized the eating symptomatology at the initial evaluation because of a sense of guilt, shame, or a lack of awareness of the eating problem, as described in literature $[37,38]$.

Nevertheless, some potential clinical implications of these data should be considered. Since the SARS-CoV-2 pandemic is far from being over, male patients with obesity should be particularly supported in treatment, owing to their higher risk of attrition. Furthermore, an investigation of affective temperaments may be particularly welcomed as a preliminary assessment for patients with obesity who seek specialized treatments for weight loss.

In conclusion, our preliminary results outlined specific characteristics of individuals with obesity who dropped out from a weight loss program during and outside the SARS$\mathrm{CoV}-2$ pandemic and may be useful for the management of these patients in the clinical practice. Further studies on larger samples are warranted since data on this important issue are currently largely lacking.

Supplementary Materials: The following supporting information can be downloaded at: https: / / www.mdpi.com/article/10.3390/jcm11030862/s1, Table S1: Characteristics of the cohort by the period of follow-up. Table S2: Attrition by the period of attendance to the obesity unit. 


\begin{abstract}
Author Contributions: Conceptualization, S.B. (Simona Bo), E.G. and G.A.-D. Methodology, S.B. (Simona Bo), S.B. (Sara Belcastro), and F.D.M.; formal analysis, S.B. (Simona Bo) and M.P.; investigation, I.G., C.D. and C.C.; data curation, S.B. (Simona Bo), E.M. and E.S.; writing-original draft preparation, E.M., M.P. and V.P.; writing-review and editing, S.B. (Simona Bo) and G.A.-D.; supervision, F.B., A.B. and E.G.; project administration, S.B. (Simona Bo) and E.S. All authors have read and agreed to the published version of the manuscript.
\end{abstract}

Funding: This research received no external funding.

Institutional Review Board Statement: The study was conducted according to the guidelines of the Declaration of Helsinki and approved by the Ethics Committee of "Città della Salute e della Scienza", University of Turin (protocol code 36671, 10 April 2020).

Informed Consent Statement: Informed consent was obtained from all subjects involved in the study.

Data Availability Statement: Anonymized data are available upon reasonable request to the last author.

Conflicts of Interest: The authors declare no conflict of interest.

\title{
References
}

1. Bornstein, S.R.; Rubino, F.; Ludwig, B.; Rietzsch, H.; Schwarz, P.E.H.; Rodionov, R.N.; Khunti, K.; Hopkins, D.; Birkenfeld, A.L.; Boehm, B.; et al. Consequences of the COVID-19 pandemic for patients with metabolic diseases. Nat. Metab. 2021, 3, $289-292$. [CrossRef] [PubMed]

2. Sjögren, L.; Stenberg, E.; Thuccani, M.; Martikainen, J.; Rylander, C.; Wallenius, V.; Olbers, T.; Kindblom, J.M. Impact of obesity on intensive care outcomes in patients with COVID-19 in Sweden-A cohort study. PLoS ONE 2021, 16, e0257891. [CrossRef] [PubMed]

3. Marik, P.E.; Chen, C. The clinical characteristics and hospital and post-hospital survival of patients with the obesity hypoventilation syndrome: Analysis of a large cohort. Obes. Sci. Pract. 2016, 2, 40-47. [CrossRef] [PubMed]

4. Gong, M.N.; Bajwa, E.K.; Thompson, B.T.; Christiani, D.C. Body mass index is associated with the development of acute respiratory distress syndrome. Thorax 2010, 65, 44-50. [CrossRef] [PubMed]

5. Fiorillo, A.; Gorwood, P. The consequences of the COVID-19 pandemic on mental health and implications for clinical practice. Eur. Psychiatry 2020, 63, e32. [CrossRef] [PubMed]

6. Weiss, F.; Barbuti, M.; Carignani, G.; Calderone, A.; Santini, F.; Maremmani, I.; Perugi, G. Psychiatric Aspects of Obesity: A Narrative Review of Pathophysiology and Psychopathology. J. Clin. Med. 2020, 9, 2344. [CrossRef] [PubMed]

7. Ryan, D.H.; Ravussin, E.; Heymsfield, S. COVID-19 and the Patient with Obesity-The Editors Speak Out. Obesity 2020, $28,847$. [CrossRef]

8. Moroshko, I.; Brennan, L.; O'Brien, P. Predictors of dropout in weight loss interventions: A systematic review of the literature. Obes. Rev. 2011, 12, 912-934. [CrossRef]

9. Ponzo, V.; Scumaci, E.; Goitre, I.; Beccuti, G.; Benso, A.; Belcastro, S.; Crespi, C.; De Michieli, F.; Pellegrini, M.; Scuntero, P.; et al. Predictors of attrition from a weight loss program. A study of adult patients with obesity in a community setting. Eat. Weight Disord. 2021, 26, 1729-1736. [CrossRef]

10. Dalle Grave, R.; Calugi, S.; El Ghoch, M. Are Personality Characteristics as Measured by the Temperament and Character Inventory (TCI) Associated with Obesity Treatment Outcomes? A Systematic Review. Curr. Obes. Rep. 2018, 7, 27-36. [CrossRef]

11. Dalle Grave, R.; Calugi, S.; Compare, A.; El Ghoch, M.; Petroni, M.L.; Colombari, S.; Minniti, A.; Marchesini, G. Personality, attrition and weight loss in treatment seeking women with obesity. Clin. Obes. 2015, 5, 266-272. [CrossRef]

12. Belteczki, Z.; Rihmer, Z.; Rozsa, S.; Ujvari, J.; Pompili, M.; Gonda, X.; Dome, P. Affective Temperaments, Panic Disorder and Their Bipolar Connections. Medicina 2021, 57, 289. [CrossRef] [PubMed]

13. Solmi, M.; Zaninotto, L.; Toffanin, T.; Veronese, N.; Lin, K.; Stubbs, B.; Fornaro, M.; Correll, C.U. A comparative meta-analysis of TEMPS scores across mood disorder patients, their first-degree relatives, healthy controls, and other psychiatric disorders. J. Affect. Disord. 2016, 196, 32-46. [CrossRef] [PubMed]

14. Marzola, E.; Porliod, A.; Panero, M.; De-Bacco, C.; Abbate-Daga, G. Affective temperaments and eating psychopathology in anorexia nervosa: Which role for anxious and depressive traits? J. Affect. Disord. 2020, 266, 374-380. [CrossRef] [PubMed]

15. Marzola, E.; Fassino, S.; Amianto, F.; Abbate-Daga, G. Affective temperaments in anorexia nervosa: The relevance of depressive and anxious traits. J. Affect. Disord. 2017, 218, 23-29. [CrossRef]

16. Scumaci, E.; Marzola, E.; Abbate-Daga, G.; Pellegrini, M.; Ponzo, V.; Goitre, I.; Benso, A.; Broglio, F.; Belcastro, S.; Crespi, C.; et al. Affective temperaments and obesity: Is there an association with binge eating episodes and multiple weight cycling? J. Affect. Disord. 2021, 295, 967-973. [CrossRef]

17. Vecsey-Nagy, M.; Szilveszter, B.; Kolossváry, M.; Boussoussou, M.; Vattay, B.; Gonda, X.; Rihmer, Z.; Merkely, B.; MaurovichHorvat, P.; Nemcsik, J. Association between affective temperaments and severe coronary artery disease. J. Affect. Disord. 2021, 295, 914-919. [CrossRef] [PubMed] 
18. Yamamoto, T.; Sakurai, K.; Watanabe, M.; Sakuma, I.; Kanahara, N.; Shiina, A.; Hasegawa, T.; Watanabe, H.; Iyo, M.; Ishibashi, R. Cyclothymic Temperament is Associated with Poor Medication Adherence and Disordered Eating in Type 2 Diabetes Patients: A Case-Control Study. Diabetes Ther. 2021, 12, 2611-2624. [CrossRef] [PubMed]

19. Moccia, L.; Janiri, D.; Pepe, M.; Dattoli, L.; Molinaro, M.; De Martin, V.; Chieffo, D.; Janiri, L.; Fiorillo, A.; Sani, G.; et al. Affective temperament, attachment style, and the psychological impact of the COVID-19 outbreak: An early report on the Italian general population. Brain Behav. Immun. 2020, 87, 75-79. [CrossRef]

20. Amann, B.; Mergl, R.; Torrent, C.; Perugi, G.; Padberg, F.; El-Gjamal, N.; Laakmann, G. Abnormal temperament in patients with morbid obesity seeking surgical treatment. J. Affect. Disord. 2009, 118, 155-160. [CrossRef]

21. Pompili, M.; Girardi, P.; Tatarelli, R.; Iliceto, P.; De Pisa, E.; Tondo, L.; Akiskal, K.K.; Akiskal, H.S. TEMPS-A (Rome): Psychometric validation of affective temperaments in clinically well subjects in mid- and south Italy. J. Affect. Disord. 2008, 107, 63-75. [CrossRef] [PubMed]

22. Di Bernardo, M.; Barciulli, E.; Ricca, V.; Mannucci, E.; Moretti, S.; Cabras, P.L.; Rotella, C.M. Binge Eating Scale in obese patients: Validation of the Italian version. Minerva Psichiatr. 1998, 39, 125-130.

23. Beck, A.T. An Inventory for Measuring Depression. Arch. Gen. Psychiatry 1961, 4, 561. [CrossRef] [PubMed]

24. Spielberger, C.D.; Gorsuch, R.L.; Lushene, R.; Vagg, P.R.; Jacobs, G.A. Manual for the State-Trait Anxiety Inventory; Consulting Psychologists Press: Palo Alto, CA, USA, 1983.

25. Rossi, A.P.; Rubele, S.; Calugi, S.; Caliari, C.; Pedelini, F.; Soave, F.; Chignola, E.; Vittoria Bazzani, P.; Mazzali, G.; Dalle Grave, R.; et al. Weight Cycling as a Risk Factor for Low Muscle Mass and Strength in a Population of Males and Females with Obesity. Obesity 2019, 27, 1068-1075. [CrossRef]

26. El Masri, D.; Itani, L.; Kreidieh, D.; Tannir, H.; El Ghoch, M. Relationship between multiple weight cycles and early weight loss in patients with obesity: A longitudinal study. Eat. Weight Disord. 2021, 26, 2083-2087. [CrossRef]

27. Schafer, K.M.; Lieberman, A.; Sever, A.C.; Joiner, T. Prevalence rates of anxiety, depressive, and eating pathology symptoms between the pre- and peri-COVID-19 eras: A meta-analysis. J. Affect. Disord. 2022, 298 Pt A, 364-372. [CrossRef]

28. Fleischmann, E.; Dalkner, N.; Fellendorf, F.T.; Reininghaus, E.Z. Psychological impact of the COVID-19 pandemic on individuals with serious mental disorders: A systematic review of the literature. World J. Psychiatry 2021, 11, 1387-1406. [CrossRef]

29. Available online: https://opendatadpc.maps.arcgis.com/apps/dashboards/b0c68bce2cce478eaac82fe38d4138b1 (accessed on 15 November 2021).

30. Available online: https://www.epicentro.iss.it/coronavirus / (accessed on 15 November 2021).

31. Chen, S.; Sun, H.; Heng, M.; Tong, X.; Geldsetzer, P.; Wang, Z.; Wu, P.; Yang, J.; Hu, Y.; Wang, C.; et al. Factors Predicting Progression to Severe COVID-19: A Competing Risk Survival Analysis of 1753 Patients in Community Isolation in Wuhan, China. Engineering 2021. [CrossRef]

32. Jiandani, D.; Wharton, S.; Rotondi, M.A.; Ardern, C.I.; Kuk, J.L. Predictors of early attrition and successful weight loss in patients attending an obesity management program. BMC Obes. 2016, 3, 14. [CrossRef]

33. Baldessarini, R.J.; Vázquez, G.H.; Tondo, L. Bipolar depression: A major unsolved challenge. Int. J. Bipolar Disord. $2020,8,1$. [CrossRef]

34. Ufholz, K.; Bhargava, D. A Review of Telemedicine Interventions for Weight Loss. Curr. Cardiovasc. Risk Rep. 2021, 15, 17. [CrossRef] [PubMed]

35. Calcaterra, V.; Verduci, E.; Vandoni, M.; Rossi, V.; Di Profio, E.; Carnevale Pellino, V.; Tranfaglia, V.; Pascuzzi, M.C.; Borsani, B.; Bosetti, A.; et al. Telehealth: A Useful Tool for the Management of Nutrition and Exercise Programs in Pediatric Obesity in the COVID-19 Era. Nutrients 2021, 13, 3689. [CrossRef] [PubMed]

36. Castrillón Liñan, C.; Alvarez Mayorga, J.H.; Lozada-Urbano, M. The effects of telenutrition in overweight and obese adults in a nutritional center in Lima, Peru. F1000Research 2021, 10, 545. [CrossRef] [PubMed]

37. Kornstein, S.G.; Kunovac, J.L.; Herman, B.K.; Culpepper, L. Recognizing binge-eating disorder in the clinical setting: A review of the literature. Prim. Care Companion J. CNS Disord. 2016, 18, 3. [CrossRef]

38. Chevinsky, J.D.; Wadden, T.A.; Chao, A.M. Binge Eating Disorder in Patients with Type 2 Diabetes: Diagnostic and Management Challenges. Diabetes Metab. Syndr. Obes. 2020, 13, 1117-1131. [CrossRef] 